\title{
Influence of LLDPE-g-MA on Mechanical Properties, Degradation Performance, and Water Absorption of Thermoplastic Sago Starch Blends
}

\author{
Denny Akbar Tanjung ${ }^{1,2}$, Novesar Jamarun ${ }^{1^{*}}$, Syukri Arief ${ }^{1}$, Hermansyah Aziz ${ }^{1}$, Ahmad Hafizullah \\ Ritonga ${ }^{1,3}$, and Boy Isfa ${ }^{1}$ \\ ${ }^{1}$ Department of Chemistry, University of Andalas, Limau Manis, Padang 25163, West Sumatera, Indonesia \\ ${ }^{2}$ Department of Agrotechnology, Faculty Agriculture, Universitas Medan Area, Medan-20223, North Sumatera, Indonesia \\ ${ }^{3}$ Department of Chemistry, Faculty of Science, Technology, and Information, University of Sari Mutiara Indonesia, Medan 20123, \\ North Sumatera, Indonesia
}

\begin{abstract}
${ }^{*}$ Corresponding author:
email: novesarjamarun@sci.unand.ac.id

Abstract: The addition of LLDPE-g-MA into the compound of sago starch/LLDPE was

Received: August 20, 2021

Accepted: November 11, 2021

DOI: $10.22146 /$ ijc. 68558 studied to improve its mechanical, morphology, degradation performance, and water absorption properties. Thermoplastic Sago Starch was composed of a mixture of sago starch and glycerol. LLDPE-g-MA was prepared in varied concentrations based on the weight of TPSS $(0,6,8,10$, and $14 w t . \%)$ by reacting LLDPE, maleic anhydride, and benzoyl peroxide using an internal mixer. The results showed an increase in values obtained from mechanical tests, i.e., tensile strength was improved from 0.6902 to 3.6187 $\mathrm{N} / \mathrm{mm}^{2}$ with the addition of LLDPE-g-MA at $10 \mathrm{wt} . \%$. The addition also resulted in a $1.44 \%$ increment in elongation at break and $251 \mathrm{~N} / \mathrm{mm}^{2}$ for Young's Modulus. The surface morphology of the sample demonstrated an excellent interfacial adhesion reaction or LLDPE dispersion over the entire surface of the matrix (starch). The water absorption test continued to decrease with the increase in the LLDPE-g-MA concentration from $53 \mathrm{wt} . \%$ (without LLDPE-g-MA) to $14 \mathrm{wt} . \%$ at $10 \mathrm{wt} . \%$ LLDPE-gMA concentration. The degradation performance showed that the sample could be degraded under all three conditions for up to 30 days.
\end{abstract}

Keywords: bioplastic; compatibilizer; coupling agent; LLDPE-g-MA; thermoplastic

\section{- INTRODUCTION}

Several ways that can be done in handling plastic waste are recycling, incineration, and burial. However, burning plastic waste can produce toxic substances that are harmful to living things and the environment. Meanwhile, planting waste has been found ineffective because plastic is difficult to degrade. Another way that has been developed to overcome the problem of plastic waste is the use of biodegradable plastics. Biodegradable plastics can be decomposed by microorganisms such as fungi, algae, and bacteria [1-2]. Unfortunately, the use of biodegradable plastics has yet to be perceived as impactful in saving the environment.

The advantages of using natural materials to make biodegradable plastics include their natural abundance, economical price, ease of accessibility, and degradability in the natural environment [3-4]. Some natural materials used as basic materials for making bioplastics are starch, cellulose, protein, and fat. However, biodegradable plastic materials have several weaknesses, including poor mechanical properties, susceptibility to high temperatures, brittleness, very low flow indices, and hydrophilicity [5-9].

The weakness of the natural material can be overcome by mixing it with synthetic materials such as Linear Low-Density Polyethylene (LLDPE), HighDensity Polyethylene (HDPE), Polypropylene (PP), and others. The advantages of these synthetic materials include resistance to high temperatures, good mechanical properties, high flow indices, elasticity, and 
hydrophobicity. However, mixing the materials can be challenging as it is difficult for the mixture of natural and synthetic materials to be homogeneous (incompatible) due to their hydrophilicity and hydrophobicity, respectively. The compatibility between the two mixtures can be improved by adding a compatibilizer, a compound capable of increasing the homogeneity of a mixture and improving the adhesion between different phases [10-13].

The most widely used compatibilizer is anhydrous maleic acid. The addition of anhydrous maleic acid is widely used because of its economic cost, low toxicity, and ease of grafting the anhydrous maleic acid onto polymers at normal melting temperatures without significant homo-polymerization. Anhydride reaction with starch hydroxyl forms esters that do not produce water during the reaction [11].

Several studies have used anhydrous maleic acid as a compatibilizer [14-15] and sago starch as a matrix [1618]. This study aimed to determine the effect of the compatibilizer (LLDPE-g-MA) on the mechanical properties, degradation performance, and water absorption of the thermoplastic mixture of sago starch. The addition of LLDPE-g-MA (LLDPE grafting anhydrous maleic acid) at varying concentrations into the thermoplastic mixture of sago starch (sago starch + glycerol) and LLDPE was expected to improve the mechanical properties of the composite, inhibit the rate of water absorption by the composite and allow for degradation of the composite under three environmental conditions.

\section{- EXPERIMENTAL SECTION}

\section{Materials}

The materials used in this study were commercial sago starch from the Parang brand of PT Warna Jaya Indonesia, anhydrous maleic acid (p.a) and benzoyl peroxide (p.a) from MERCK-Germany, glycerol (p.a), and Low Linear Density of Polyethylene (LLDPE) UF 1810S1 pellet (density: $0.922 \mathrm{~g} / \mathrm{m}^{3}$, melt Index $\left(190^{\circ} \mathrm{C} / 2.16 \mathrm{~kg}\right)$ of $1.0 \mathrm{~g} / 10 \mathrm{~min}$, melt point of $122{ }^{\circ} \mathrm{C}$ ) from PT Chandra Asri- Indonesia, and distilled water.

\section{Procedure}

\section{Preparation of TPSS}

TPSS was made by reacting sago starch with glycerol plus water as a solvent. The ratio of sago starch and glycerol was $65: 35 \mathrm{wt} . \%$ [19]. Therefore, the amount of water added was $250 \%$ of the total mixture. First, the mixture was heated at $100{ }^{\circ} \mathrm{C}$ until it formed gelatin. Then, the water content of the gelatin was reduced by drying for $24 \mathrm{~h}$ at $80^{\circ} \mathrm{C}$, which could reduce the water content to $5 \%$.

\section{Preparation of compatibilizer}

The compounds were mixed using an internal mixer (Haake Polydrive Thermo). LLDPE was firstly added into the mixing chamber, followed by anhydrous maleic acid after 5 min of mixing, before finally being added with BPO. The mixture was incubated at $150{ }^{\circ} \mathrm{C}$ and shaken at $100 \mathrm{rpm}$, for $13 \mathrm{~min}$. The composition of the mixture with added compatibilizer was $88 \mathrm{wt} . \%$ LLDPE, 9 wt.\% anhydrous maleic acid, and 3 wt.\% benzoyl peroxide. The mixture was cooled down and cut into pellets with $3 \mathrm{~mm} \times 2 \mathrm{~mm} \times 2 \mathrm{~mm}$.

\section{Preparation of TPSS/LLDPE/PE-g-MA blends}

The final phase of this research involved the preparation of TPSS/LLDPE/PE-g-MA blends made of TPSS, LLDPE, and compatibilizer, with the ratio of TPSS to LLDPE, 80:20 wt.\%. In addition, the concentration of compatibilizer was varied from $0,6,8,10,12$ to 14 wt.\% based on TPSS weight.

\section{Characterization}

Compression molding. The Thermoplastic Sago Starch (TPSS)/LLDPE blends were molded via electric heating hydraulic compression. The procedures involved melting by preheating at $150{ }^{\circ} \mathrm{C}$ for $5 \mathrm{~min}$, followed by compression at maximum pressure for $10 \mathrm{~min}$ at $150^{\circ} \mathrm{C}$. The mixture was molded according to the specimen of ASTM D638.

Spectroscopy Fourier Transform Infra-Red (FTIR). Spectroscopy Fourier Transform Infra-Red (FTIR; Perkin Elmer System 2000) was used to obtain qualitative information of the groups and chemical 
characteristics of the TPSS/LLDPE blends. For each spectrum, 32 scans were consecutively recorded at a resolution of $16 \mathrm{~cm}^{-1}$. The samples were measured in a layer with a thickness of $1 \mathrm{~mm}$, prepared via hot press molding.

Tensile properties. Testing the mechanical properties of biodegradable plastics is necessary to determine the homogeneity of the mixture or interactions between polymers. Therefore, a tensile test was carried out using the Universal Band Tensilon with the specimen of ASTM D638 Type 1 . The chamber temperature was set at $25^{\circ} \mathrm{C}$, with humidity of $60 \% \mathrm{RH}$ and $10 \mathrm{~mm}$ speed $/ \mathrm{min}$. Three specimens were used to obtain the average value of tensile strength, elongation at break, and Young's modulus.

Test of morphology. Scanning Electron Microscopy (SEM) test was performed to evaluate the surface morphology of the TPSS/LLDPE mixture. Samples were dried in an oven to reduce moisture content and avoid electrostatic charging and poor resolution. Before the surface inspection, the sample was mounted on a piece of aluminum and a sputter, coated with a thin layer of gold.

Water absorption test. The water absorption test was carried out to investigate the ability of the TPSS/LLDPE compatibilizer mixture to absorb water. First, the sampling sheet was cut into a dimension of $20 \mathrm{~mm} \times 20 \mathrm{~mm}$ [15] with a thickness of $3 \mathrm{~mm}$. Next, the sheet was washed with distilled water, dried up to $80 \mathrm{wt} . \%$ for $12 \mathrm{~h}$, then cooled down in a desiccator and weighed to gain initial weight. It was then immersed into aquadest for 10 days in the chamber at $28-30{ }^{\circ} \mathrm{C}$ and reweighed.

Biodegradability test. The compatible blend of TPSS/LLDPE with a dimension of $20 \mathrm{~mm} \times 20 \mathrm{~mm}$ and a thickness of $3 \mathrm{~mm}$ was examined under different controlled conditions [20]. The sample was immersed in freshwater in the first condition and seawater in the second condition. The weight loss was measured every 10 , 20 , and 30 days. The hollow container was filled with soil, and the sample was buried $10 \mathrm{~mm}$ deep from the surface of the alluvial soil [15]. The soil was regularly wet to keep the humidity. The weight loss in the sample was monitored regularly every 10,20 , and 30 days. The test was carried out by washing the sample with distilled water, drying it in the chamber, and weighing until the measured weight was constant. The degradation test in the three environmental conditions was carried out indoors, with the humidity kept at $45-65 \% \mathrm{RH}$.

Thermogravimetric Analysis (TGA). The Thermogravimetric was carried out according to the STA module with a channel TGDTA 7,300. The sample used in this test was $7.73 \mathrm{mg}$ with a heating rate of $10{ }^{\circ} \mathrm{C} / \mathrm{min}$, increasing from 30 to $650{ }^{\circ} \mathrm{C}$. The flow rate of nitrogen gas was set at $50 \mathrm{~mL} / \mathrm{min}$.

\section{- RESULTS AND DISCUSSION}

In Fig. 1, the spectrum of all mixtures with and without the compatibilizer shows characteristic peaks at 970-1080 and $3000-3650 \mathrm{~cm}^{-1}$, indicating the presence of $\mathrm{COO}$ and hydroxyl, respectively. The new peak at $1707 \mathrm{~cm}^{-1}$ observed in each spectrum of the sago starch/LLDPE mixture with added compatibilizer was identified as an ester group formed from a hydroxyl reaction $\left(3265 \mathrm{~cm}^{-1}\right)$ with an anhydride functional group in the TPSS. The formation of an ester group was also reported in previous studies [19]. It was also observed that the same peaks are present in all graphs, except those without the compatibilizer. Such difference was due to the small amount of compatibilizer (\%) present in the mixture as determined based on the TPSS weight.

Fig. 2 shows that the values measured for tensile strength, Young's Modulus, and elongation at break

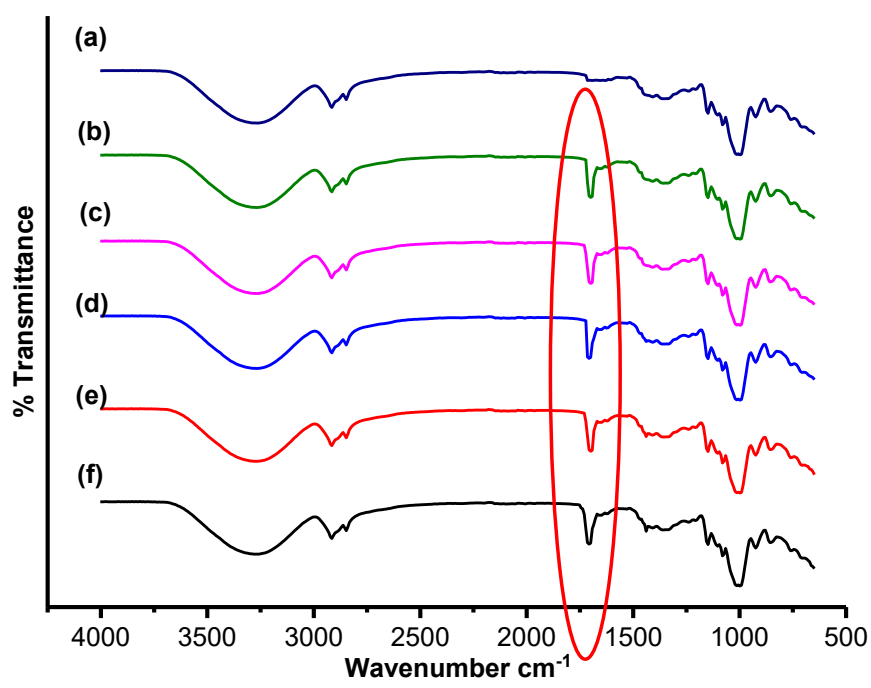

Fig 1. FTIR spectra of TPSS/LLDPE (a) $0 \%$, (b) 4\%, (c) $6 \%$, (d) $8 \%$, (e) $10 \%$, (d) $12 \%$, and (f) Compatibilizer $14 \%$ 
significantly increased after adding a compatibilizer. The maximum peak was obtained with the addition of $10 \mathrm{wt} . \%$ LLDPE, resulting in values of $3.6187 \mathrm{~N} / \mathrm{mm}^{2}$ for tensile strength, 1.44\% for Young's Modulus, and $251 \mathrm{~N} / \mathrm{mm}^{2}$ for elongation at break. The complete data are presented in Table 1.

The addition of a compatibilizer tends to increase the tensile strength by facilitating the interaction between starch (matrix) and LLDPE to make the mixture more homogeneous or compatible [19]. This study reported an increase in the tensile strength of the mixture from 0.6902 $\mathrm{N} / \mathrm{mm}^{2}$ (without compatibilizer) to $3.6187 \mathrm{~N} / \mathrm{mm}^{2}$ (with compatibilizer at $10 \mathrm{wt} . \%)$.

Compatibility has also been associated with the increase in flexibility or decrease in stiffness, as the compatibilizer acts as a bridge between hydrophobic (LLDPE) and hydrophilic (TPSS) components [21-22]. However, under certain conditions, increasing the compatibilizer's concentration may weaken the mixture's mechanical properties. It is safe to deduce that the interaction between the TPSS and LLDPE is only physical, which reduces the adhesion force between the surfaces of the hydrophilic and hydrophobic polymer groups, despite being connected by a coupling agent. Previous studies have reported that the decrease in tensile strength was due to homopolymerization that caused the maleic anhydride monomers to bind themselves instead of binding to the LLDPE chain [7].

Fig. 3(a) shows a TPSS/LLDPE blend without compatibilizer at a 1:500 scale. The image shows that the LLDPE polymer was not evenly distributed in the starch

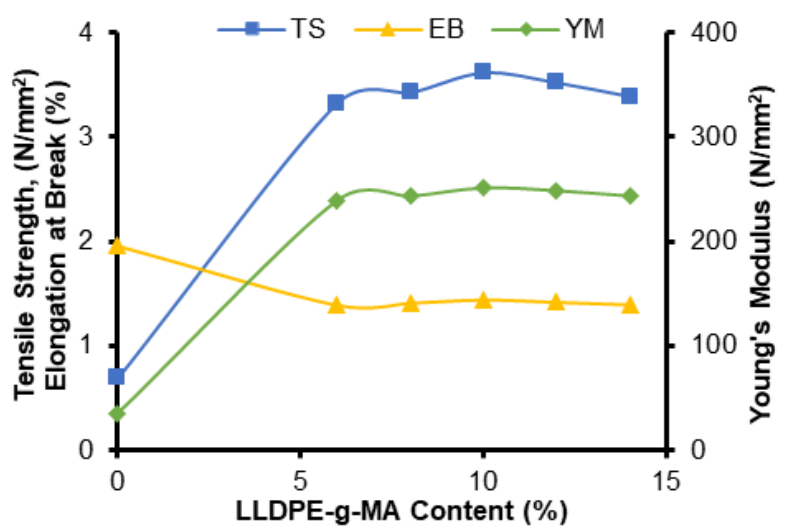

Fig 2. Tensile strength (TS), elongation at breaks (EB) and Young's Modulus (YM) test of TPSS/LLDPE blends

Table 1. Data of mechanical properties

\begin{tabular}{lccccc}
\hline No. & $\begin{array}{c}\text { Compatibilizer } \\
\text { content }(\%)\end{array}$ & $\begin{array}{c}\text { Density } \\
\mathrm{g} / \mathrm{mm}^{3}\end{array}$ & $\begin{array}{c}\text { Tensile strength } \\
\left(\mathrm{N} / \mathrm{mm}^{2}\right)\end{array}$ & $\begin{array}{c}\text { Elongation } \\
\text { at breaks }(\%)\end{array}$ & $\begin{array}{c}\text { Young's Modulus } \\
\left(\mathrm{N} / \mathrm{mm}^{2}\right)\end{array}$ \\
\hline 1 & 0 & 1.2612 & 0.6902 & 1.96 & 35 \\
2 & 6 & 1.2635 & 3.3256 & 1.39 & 239 \\
3 & 8 & 1.2606 & 3.4273 & 1.41 & 243 \\
4 & 10 & 1.2620 & 3.6187 & 1.44 & 251 \\
5 & 12 & 1.2618 & 3.5243 & 1.42 & 248 \\
6 & 14 & 1.2631 & 3.3930 & 1.39 & 243 \\
\hline
\end{tabular}
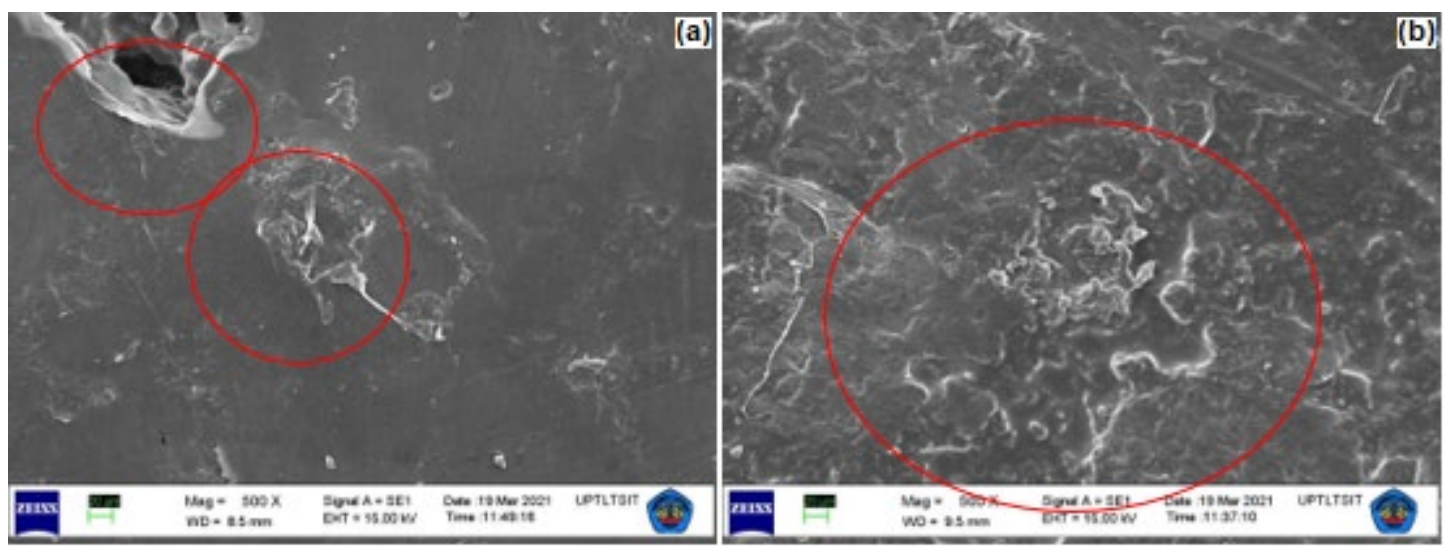

Fig 3. SEM image of (a) Uncompatibilizer, (b) Compatibilizer content $10 \mathrm{wt. \% )}$ 
matrix. The difference in polarity between the two polymers was the cause of non-homogeneity in the mixture (incompatibility). Fig. 3(b) shows the surface morphology of TPSS/LLDPE with added compatibilizer, which demonstrated an even distribution of LLDPE in the starch matrix as the compatibilizer acted as a coupling agent. The use of a compatibilizer improved the surface adhesion between LLDPE and starch. This data was supported by the mechanical test results, which showed that the addition of a $10 \%$ compatibilizer increased the tensile strength compared to that without a compatibilizer.

One of the disadvantages of using starch as a basic material for making bioplastics is its high capacity to absorb water. This study found that without the addition of a compatibilizer, the TPSS/LLDPE mixture could absorb water up to $54 \%$ (see Fig. 4) due to the large number of starch hydroxyl groups that were not bound to the synthetic polymers (LLDPE) as the latter exhibited hydrophobicity in the presence of water. The minimal water absorption (14\%) was achieved with the addition of a compatibilizer at $10 \mathrm{wt} . \%$. Further increase in the compatibilizer concentration only resulted in an insignificant increase in the water absorption curve.

The advantage of using bioplastics includes their ability to degrade rapidly in the environment. The degradation tests were carried out under several conditions, i.e., in freshwater, seawater, and soil. Degradation in freshwater, the mixture with a compatibilizer of $10 \%$ achieved a mass loss of $47 \%$, compared to the uncompatibilzer mixture (14\%) (Fig. 5). In seawater, a mass loss of $44 \%$ was recorded with the addition of $10 \mathrm{wt} \%$ compatibilizers compared to that without a compatibilizer (14\%). Such observation was due to the high molecular weight of seawater that made it difficult for the hydroxyl groups in starch to react with seawater molecules.

In the soil, the degradation was measured with a mass loss of $30 \%$ in the mixture added with 10 wt.\% compatibilizers as compared to that without a compatibilizer $(28 \%)$. It can be deduced that the compatibilizer exhibited maximum effectiveness as a coupling agent between starch (hydrophilic) and LLDPE (hydrophobic) at a concentration of $10 \mathrm{wt} . \%$. This finding

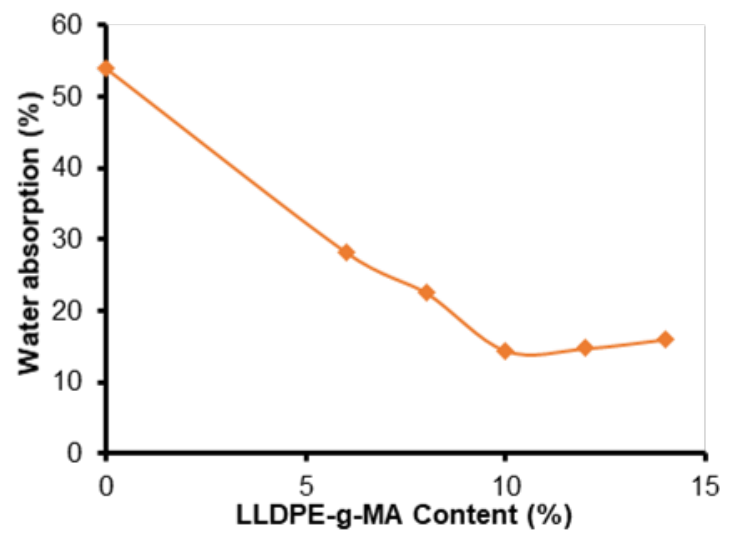

Fig 4. Water absorption of TPSS/LLDPE/compatibilizer blends

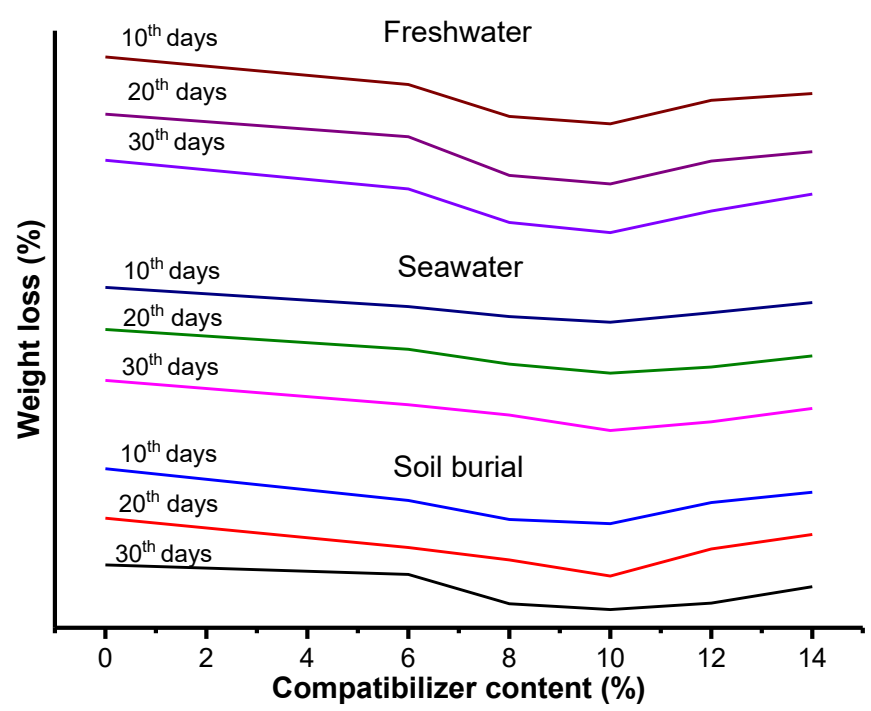

Fig 5. Degradation test in freshwater, seawater, and soil burial

was supported by results obtained in mechanical and water absorption tests, which showed that the maximum values were obtained with the addition of $10 \mathrm{wt} . \%$ compatibilizers. Meanwhile, the degradability test showed that the highest degradation rate in freshwater, followed by seawater and soil. The compatibilizer (LLDPE-g-MA) has an inhibitory effect on the biodegradation of the mixture in the soil due to PP-gMA interactions. The chemical bond between the anhydride group of PP-g-MA and the hydride group of starch could prevent the absorption of starch by microorganisms in the soil [23-24].

The thermal-gravimetric analysis technique was performed to determine the thermal decomposition and 


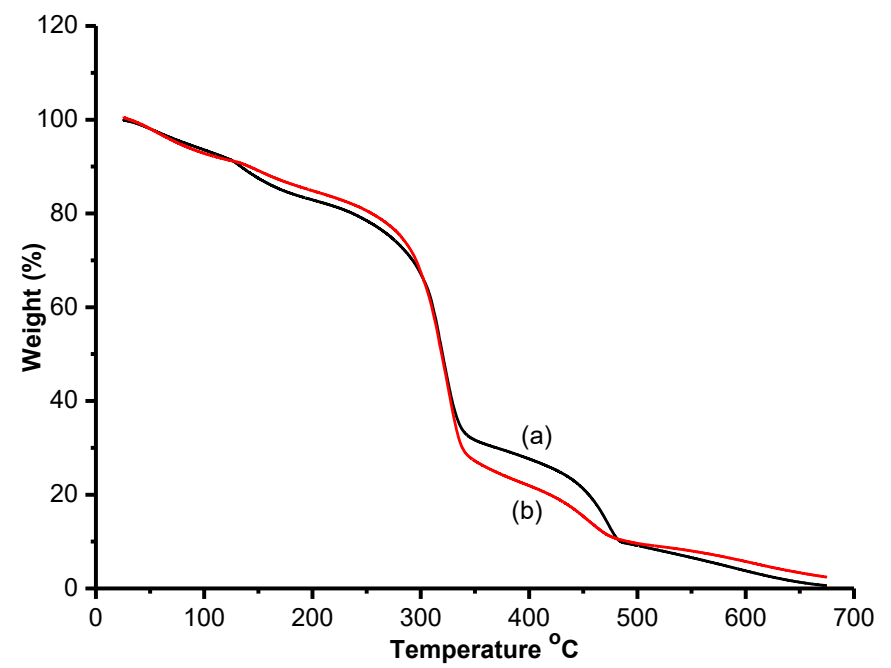

Fig 6. TGA curve of (a) Compatibilizer 10wt.\%, (b) Uncompatibilizer

stability of TPSS/LLDPE blends. Fig. 6 shows no difference between the spectra of samples with and without the addition of compatibilizer, except in stage 3. Based on the spectrum in Fig. 6, it can be observed that there is no difference between the two spectra. However, in Stage 3, the percentage of weight degradation with the compatibilizer is slightly higher because the compatibilizer contains LLDPE, which is degraded at this stage.

The thermogravimetric analysis confirmed that the degradation occurred in stage 4 . In the first stage, which was carried out at $201{ }^{\circ} \mathrm{C}$, only water and glycerol were degraded. Evaporation (up to 6\%) occurred in stage 1 as water decomposed into $\mathrm{O}_{2}$ and $\mathrm{H}_{2}$ at $100{ }^{\circ} \mathrm{C}$. In stage 2, which was carried out at $125-290{ }^{\circ} \mathrm{C}$, plasticizer compounds (glycerol) degradation [25-26] continued as the temperature increased, forming simpler compounds. The initial thermal degradation of starch occurred at $300{ }^{\circ} \mathrm{C}$, and LLDPE started to degrade into gas and hydrocarbon oil at $400{ }^{\circ} \mathrm{C}$ in stage 3 [27-28]. The process of thermal degradation of LLDPE continued as the temperature increased, forming simpler compounds.

\section{- CONCLUSION}

The addition of a compatibilizer as a coupling agent into the Sago Starch/LLDPE blends can improve the interface and adhesion properties of the mixture, as proven in the improved mechanical properties reported in this study. The tensile test value increased from $0.6902 \mathrm{~N} / \mathrm{mm}^{2}$ (without a compatibilizer) to $3.6187 \mathrm{~N} / \mathrm{mm}^{2}$ (with $10 \mathrm{wt} . \%$ compatibilizer). However, up to a certain concentration, the addition of the compatibilizer reached its saturation point that further increase in concentration did not affect its mechanical properties. The FTIR spectrum showed the formation of an ester group from the reaction of a hydroxyl group with an anhydrous group. The surface morphology of the samples showed that LLDPE was evenly distributed in the starch matrix. The degradation test in three environmental conditions demonstrated that the mixture of Sago starch and LLDPE could be degraded within 30 days. Results from TGA analysis indicated that thermal degradation occurred stably as no significant degradation was observed.

\section{- ACKNOWLEDGMENTS}

The author would thank the Education Funding Management Institute (LPDP) for funding this doctoral dissertation research.

\section{- REFERENCES}

[1] Kumar, M., Mohanty, S., Nayak, S.K., and Parvaiz, M.R., 2010, Effect of glycidyl methacrylate (GMA) on the thermal, mechanical and morphological property of biodegradable PLA/PBAT blend and its nanocomposites, Bioresour. Technol., 101 (21), 8406-8415.

[2] Zoungranan, Y., Lynda, E., Dobi-Brice, K.K., Tchirioua, E., Bakary, C., and Yannick, D.D., 2020, Influence of natural factors on the biodegradation of simple and composite bioplastics based on cassava starch and corn starch, J. Environ. Chem. Eng., 8 (5), 104396.

[3] Amin, M.R., Chowdhury, M.A., and Kowser, M.A., 2019, Characterization and performance analysis of composite bioplastics synthesized using titanium dioxide nanoparticles with corn starch, Heliyon, 5 (8), e02009.

[4] Thiruchelvi, R., Das, A., and Sikdar, E., 2020, Bioplastics as better alternative to petro plastic, Mater. Today: Proc., 37, 1634-1639.

[5] Méité, N., Konan, L.K., Tognonvi, M.T., Doubi, B.I.H.G., Gomina, M., and Oyetola, S., 2021, 
Properties of hydric and biodegradability of cassava starch-based bioplastics reinforced with thermally modified kaolin, Carbohydr. Polym., 254, 117322.

[6] Ezeoha, S.L., and Ezenwanne, J.N., 2013, Production of biodegradable plastic packaging film from cassava starch, IOSR J. Eng., 3 (10), 14-20.

[7] Ashok, A., Abhijith, R., and Rejeesh, C.R., 2018, Material characterization of starch derived biodegradable plastics and its mechanical property estimation, Mater. Today: Proc., 5 (1), 2163-2170.

[8] Garg, S., and Jana, A.K., 2014, Preparation of LDPEacetylated/butyrylated starch blend blow films and characterization, Chin. J. Polym. Sci., 32 (3), 268-279.

[9] Zárate-Ramírez, L.S., Romero, A., Bengoechea, C., Partal, P., and Guerrero, A., 2014, Thermomechanical and hydrophilic properties of polysaccharide/gluten-based bioplastics, Carbohydr. Polym., 112, 16-23.

[10] Imre, B., and Pukánszky, B., 2013, Compatibilization in bio-based and biodegradable polymer blends, Eur. Polym. J., 49 (6), 1215-1233.

[11] Mengual, A., Juárez, D., Balart, R., and Ferrándiz, S., 2017, PE-g-MA, PP-g-MA and SEBS-g-MA compatibilizers used in material blends, Procedia Manuf., 13, 321-326.

[12] Panrong, T., Karbowiak, T., and Harnkarnsujarit, N., 2020, Effects of acetylated and octenyl-succinated starch on properties and release of green tea compounded starch/LLDPE blend films, J. Food Eng., 284, 110057.

[13] Pavlík, Z., Pavlíková, M., and Záleská, M., 2019, "Properties of Concrete with Plastic Polypropylene Aggregates" in Use of Recycled Plastics in Eco-efficient Concrete, Eds. Pacheco-Torgal, F., Khatib, J., Colangelo, F., and Tuladhar, R., Woodhead Publishing, UK, 189-213.

[14] Obasi, H.C., Egeolu, F.C., and Oparaji, O.D., 2015, Comparative analysis of the tensile and biodegradable performances of some selected modified starch filled polypropylene blends, Am. J. Chem. Mater. Sci., 2 (2), 6-13.

[15] Obasi, H.C., and Igwe, I.O., 2014, Cassava starchmixed polypropylene biodegradable polymer:
Preparation, characterization and effects of biodegradation products on growth of plants, Int. J. Sci. Res., 3 (7), 802-807.

[16] Abdorreza, M.N., Cheng, L.H., and Karim, A.A., 2011, Effects of plasticizers on thermal properties and heat sealability of sago starch films, Food Hydrocolloids, 25 (1), 56-60.

[17] Zaman, H.U., and Beg, M.D.H., 2021, Study on binary low-density polyethylene (LDPE)/ thermoplastic sago starch (TPS) blend composites, Prog. Appl. Sci. Technol., 11 (1), 53-65.

[18] Ramírez-Hernández, A., Hernández-Mota, C.E., Páramo-Calderón, D.E., González-García, G., BáezGarcía, E., Rangel-Porras, G., Vargas-Torres, A., and Aparicio-Saguilán, A., 2020, Thermal, morphological and structural characterization of a copolymer of starch and polyethylene, Carbohydr. Res., 488, 107907.

[19] Abdul Majid, R., Ismail, H., and Mat Taib, R., 2009, Effects of PE-g-MA on tensile properties, morphology and water absorption of LDPE/ thermoplastic sago starch blends, Polym.-Plast. Technol. Eng., 48 (9), 919-924.

[20] Maran, J.P., Sivakumar, V., Thirugnanasambandham, K., and Sridhar, R., 2014, Degradation behavior of biocomposites based on cassava starch buried under indoor soil conditions, Carbohydr. Polym., 101 (1), 20-28.

[21] Mayasari, H.E., Setyorini, I., and Yuniari, A., 2019, The blending of EPDM/NR with maleic anhydride as compatibilizer: Comparing the effect of accelerators on cure characteristic and mechanical properties, Indones. J. Chem., 19 (1), 106-114.

[22] Islam, H.B.M.Z., Susan, M.A.B.H., and Imran, A.B., 2020, Effects of plasticizers and clays on the physical, chemical, mechanical, thermal, and morphological properties of potato starch-based nanocomposite films, ACS Omega, 5 (28), 17543-17552.

[23] Changwichan, K., Silalertruksa, T., and Gheewala, S.H., 2018, Eco-efficiency assessment of bioplastics production systems and end-of-life options, Sustainability, 10 (4), 1-15.

[24] Polman, E.M.N., Gruter, G.J.M., Parsons, J.R., and 
Tietema, A., 2021, Comparison of the aerobic biodegradation of biopolymers and the corresponding bioplastics: A review, Sci. Total Environ., 753, 141953.

[25] Wang, Y.G., Nie, X.A., and Liu, Z.X., 2014, Biodiesel synthesis from styrax tonkinensis catalyzed by $\mathrm{S}_{2} \mathrm{O}_{8}{ }^{2-}$ $/ \mathrm{ZrO}_{2}-\mathrm{TiO}_{2}-\mathrm{Fe}_{3} \mathrm{O}_{4}$, Appl. Mech. Mater., 521, 621-625.

[26] Sahari, J., Sapuan, S.M., Zainudin, E.S., and Maleque, M.A., 2013, Thermo-mechanical behaviors of thermoplastic starch derived from sugar palm tree
(Arenga pinnata), Carbohydr. Polym., 92 (2), 17111716.

[27] Nascimento, T.A., Calado, V., and Carvalho, C.W.P., 2012, Development and characterization of flexible film based on starch and passion fruit mesocarp flour with nanoparticles, Food Res. Int., 49 (1), 588-595.

[28] Bagri, R., and Williams, P.T., 2002, Catalytic pyrolysis of polyethylene, J. Anal. Appl. Pyrolysis, 63 (1), 29-41. 